\title{
PREPARATION AND CHARACTERIZATION OF GOATSKIN GELATIN AS HALAL ALTERNATIVE TO BOVINE GELATIN
}

\author{
A. Bahar ${ }^{1}$, N. Kusumawati ${ }^{2, *}$ and S. Muslim ${ }^{3}$ \\ ${ }^{1}$ Department of Family Welfare Education, Universitas Negeri Surabaya, \\ Surabaya, Indonesia \\ ${ }^{2}$ Department of Chemistry, Universitas Negeri Surabaya, Surabaya, Indonesia \\ ${ }^{3}$ Department of Electrical Engineering, Universitas Negeri Surabaya, Surabaya, Indonesia \\ *E-mail: nkusumawati82@yahoo.com
}

\begin{abstract}
Goatskin gelatin (GSG) produced with and without neutralization using hydrochloric acid $0,1 \mathrm{~N}$ and different extraction temperatures have been prepared. The physicochemical, mechanical and organoleptic properties are characterized and compared as an alternative to bovine skin gelatin. Application of neutralization using $\mathrm{HCl} 0.1 \mathrm{~N}$ with longest neutralization time (25 minutes) has significantly decreased water content $(11.60 \%$ to $5.00 \%)$, $\mathrm{pH}$ levels (7.44 to 6.06), viscosity (35.0 mps to $8.8 \mathrm{mps}$ ), and gel strength (0 bloom-75 bloom), while ash content and yield increased, each was $2.01 \%$ to $2.28 \%$ and $8.95 \%$ to $10.41 \%$. There was no significant change in the organoleptic properties of gelatin. Meanwhile, the combination of a specific extraction temperature increase $\left(64{ }^{\circ} \mathrm{C}\right.$ and $68{ }^{\circ} \mathrm{C}$ ) and longest neutralization time has increased gelatin yield (5.95\% to $\left.10.41 \%\right)$, water content (3.09\% to $7.63 \%)$ as well as viscosity $(7.5 \mathrm{mps}$ to $8.8 \mathrm{mps})$, and decreased ash content $(3.81 \%$ to $2.28 \%)$, pH level (6.52 to 6.06) also gel strength (218.66 bloom to 20.0 bloom). It is also not found changes in organoleptic properties in this condition, especially taste and vapor. Nevertheless, brighter colors (higher L* values) in goatskin gelatin were produced from moderate neutralization time and extraction temperatures.
\end{abstract}

Keywords: Collagen, Gelatin, Goatskin, Base Curing, Extraction.

(c) RASĀYAN. All rights reserved

\section{INTRODUCTION}

Gelatin is a protein resulting from thermal denaturation of collagen, which generally has a high molecular weight (MW). ${ }^{1}$ The process of converting collagen to gelatin is done through pretreatment (curing) in acids or bases which will eliminate the collagen original structure through triple helix decomposition into a double or even a single helix. Finally, the conversion takes place during extraction with heat, which is accompanied by hydrolysis in water media. ${ }^{2}$

Gelatin is a multifunctional material that is widely used by the food, cosmetics, pharmaceutical, medical, photography, and vehicle industries. ${ }^{3-5}$ Besides, gelatin also has many applications in the packaging industry based on biomedical and biomaterials industrial. ${ }^{6-9}$ Of the large scale of gelatin utilization, the food industry occupies the top position as the user through application in the manufacture of additives in foods such as thickening agents, stabilizers, texturizers, and gelling agents. ${ }^{9-11}$ Gelatin production throughout the world in the period 2015-2018 has increased, namely from 412,700 tons in 2015 to 450,000 tons in $2018 .{ }^{12,13}$

The main commercial gelatin source is porcine as well as bovine skin and bone14. Although this application is widespread, consumers' strong concern about the source of gelatin continues, especially relating to religious restrictions or health problems. ${ }^{9,14}$ Increased demand for non-bovine gelatin occurs with the emergence of a bovine spongiform encephalopathy crisis and a ban on consumption for Hindus. While porcine gelatin is unacceptable in Kosher and halal foods. Muslim Halal Law requires the use of various products that are free of pork and their derivatives. ${ }^{15,16}$ Besides, concerns about bovine and porcine gelatin, also appear in the utilization of poultry gelatin due to the rampant cases of avian

Rasayan J. Chem., 13(1), 85-98(2019)

http://dx.doi.org/10.31788/RJC.2019.1245409

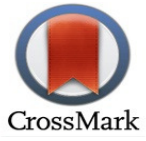


RASĀYAN J. Chem.

Vol. 13 | No. 1 |85 - 98| January - March | 2020

influenza. As a result, demand for gelatin from potential alternative sources, such as those produced from the goat slaughtering industry (skin or bone) has increased significantly. A total of 6.4 to $11.6 \mathrm{~g}$ of goatskin is produced per $100 \mathrm{~g}$ of the total weight of the slaughtered goat. ${ }^{17}$

The raw materials pre-treatment becomes an important part of extraction, which also influences the nature of the resulting gelatin. ${ }^{13}$ Generally, type A (acid) gelatin is produced by weak acid pretreatment, whereas type B (base) gelatin is generated by pretreatment using a strong base. ${ }^{18-24}$ In general, gelatin from skin material extracted which is preceded by acid/base pretreatment and extraction using a water solvent with a specific temperature in the range of $60-100{ }^{\circ} \mathrm{C}$.

The previous research has performed base extraction procedures of skin material with a different curing time in $\mathrm{CaO}$ (10, 30 and 50 days) and extraction times (4, 5 and 6 hours). ${ }^{2}$ The results show that the application of curing and extraction for a long time without accompanying the appropriate neutralizing method after curing has produced a gelatin product with ash content and $\mathrm{pH}$ that does not meet the standards set by the Gelatin Manufacturer Institute of America (GMIA). This condition is triggered by the non-neutralization of the base curing solution adsorbed in the skin material by the neutralization process using running water. Besides, the application of high extraction temperatures, particularly at the third extraction stage, has resulted in most of the skin's material being destroyed thus reducing the potential for gelatin yield. To increase the yield percentage and to produce the quality that meets GMIA standards, pretreatment using acid optimized and appropriate extraction temperatures were employed. ${ }^{25-27}$

\section{Material and Methods}

\section{EXPERIMENTAL}

In this study, calcium oxide $(\mathrm{CaO})$ was used for pre-treatment, while hydrochloric acid $(\mathrm{HCl})$ was used to neutralize raw materials after pre-treatment. Both were analytical grade and obtained from Sigma-Aldrich (Singapore).

\section{General Procedure}

Skins derived from random-age goats were collected from slaughterhouses in the Pegirian-Surabaya, Indonesia. As a sample, as many as ten kilograms of goatskin were randomly drawn from twenty different goats. To avoid physiological damage, the skin sample is put into a polyethylene bag placed in an iceisolated box and brought to the study site within 2 hours. Immediately after arriving at the location, the skin was washed thoroughly with running water $\left(28-30{ }^{\circ} \mathrm{C}\right)$ and cut $1 \times 3 \mathrm{~cm}$ in size, put into a polyethylene package and cooled to $-20^{\circ} \mathrm{C}$ (max for 2 months). Frozen skin material must be thawed under running water $\left(28-30^{\circ} \mathrm{C}\right)$ for 15 minutes.

Skin that has been prepared previously was treated by immersing in $10 \%(\mathrm{w} / \mathrm{v}) \mathrm{CaO}$ curing solution using a ratio of 1:1 (w/v). Immersing was done at room temperature. To ensure a homogeneous immersing process of goatskin in curing solution, the mixture was stirred for 5 minutes every two days. Based on pretreatment procedures that have been reported in previous publications, curing was performed for 30 days. $^{2}$

After the curing process is completed, the skins were washed with running water and then neutralized by immersion in $\mathrm{HCl}$ solution $2 \%(\mathrm{v} / \mathrm{v})$ during a specific time and then rinsed using running water. To determine the effect of immersion time in $\mathrm{HCl}$ solution to the optimum neutralizing process, the immersion time is varied, i.e., for 5; 15 and 25 minutes. The goatskin material produced from this stage is ready for extracting.

\section{Gelatin Extraction}

Pre-treated skins were through the first extraction in a distilled water medium with a temperature of $60{ }^{\circ} \mathrm{C}$ for 4 hours. The extraction process was carried out with a skin/water ratio of $1: 1(\mathrm{w} / \mathrm{v})$. The extract obtained was filtered using two layers of fabric. The resulting filtrate was heated at $50{ }^{\circ} \mathrm{C}$ until a quarter of the initial volume was obtained, followed by the drying process using the oven at the same temperature to obtain a gelatin product with water content below $16 \%$. The second and third extraction processes were carried out by the same procedure, but with the temperature increasing to 62 and $64^{\circ} \mathrm{C}$, respectively. To 
determine the extraction temperature effect against yield percentage and gelatin quality obtained, at this stage the third stage extraction time is made varies including 66 and $68^{\circ} \mathrm{C}$.

\section{Yield}

The resulting gelatin is calculated using Eq. (1):

$$
Y_{i e l d}=\frac{\text { Weight of freeze }- \text { dried gelatin }(g)}{\text { Weight of initial dry shin }} \times 100 \%
$$

Water Content

Weighted gelatin samples were heated for $16-18$ hours at $105 \pm 2{ }^{\circ} \mathrm{C}$ and then re-weighed. The water content at this analysis was defined as the percentage of sample weight loss. Measurements were made in triplicate.

\section{Ash Content}

Gelatin was ashed in a crucible at $550{ }^{\circ} \mathrm{C}$ using a muffle furnace. The ash content in this analysis was determined by differential weighing and the results were interpreted as the weight percentage of the original sample.

\section{Gel Strength}

Gel strength was the gel rigidity parameter produced by $6.67 \%(\mathrm{w} / \mathrm{v})$ of gelatin prepared under certain conditions randomly determined. Bloom was a measure of strength (weight) required to compress the designated area of the sample surface by a distance of $4 \mathrm{~mm}$.

\section{Viscosity}

$6.67 \%(\mathrm{w} / \mathrm{v})$ gelatin viscosity was specifically analyzed at $60{ }^{\circ} \mathrm{C}$ from the measurement of the flow time of $100 \mathrm{~mL}$ of solution using a standard pipette.

\section{pH}

$1.5 \%(\mathrm{w} / \mathrm{v})$ gelatin $\mathrm{pH}$ was determined with potentiometry at a temperature of $35 \pm 1{ }^{\circ} \mathrm{C}$ using a $\mathrm{pH}$ meter.

\section{Organoleptic Properties}

The coordinates of CieLab $\left(\mathrm{L}^{*}, \mathrm{a}^{*}, \mathrm{~b}^{*}\right)$ of $\left(6.67 \mathrm{~g} / 100 \mathrm{ml}, 60^{\circ} \mathrm{C}\right)$ gelatin were determined by spectrophotocolorimeter (Tintometre, Lovibond PFX 195 V 3.2, Amesbury, UK). In this system, L* represents lightness, 0 (black) to 100 (white); $a^{*}$ was red/green coordinates, -100 (greenish) to +100 (reddish) and $\mathrm{b}^{*}$ was yellow/blue coordinates, -100 (bluish) to +100 (yellowish). The color difference $(\Delta \mathrm{E}$ *) is determined using Eq. (2). ${ }^{28}$

$$
\Delta E^{*}=\sqrt{\left(\Delta L^{*}\right)^{2}+\left(\Delta a^{*}\right)^{2}+\left(\Delta b^{*}\right)^{2}}
$$

\section{Fourier Transformed Infrared (FTIR) Spectroscopy}

The best-qualified goatskin gelatin IR spectra were analyzed at $25 \pm 2{ }^{\circ} \mathrm{C}$ using FTIR spectrophotometers (Frontier, Perkin Elmer, USA) at wavenumbers $500-4000 \mathrm{~cm}^{-1}$. Two milligrams of gelatin sample in 100 $\mathrm{mg} \mathrm{KBr}$ was placed in a disc.

\section{Yield}

\section{RESULTS AND DISCUSSION}

The goatskin gelatin yield under base curing with different neutralization times and extraction temperature were shown in Table-1. The gelatin yield from many different operational conditions varies in the range of $5.17-10.41 \%$. Gelatin from goatskin without post-curing neutralization and with third extraction temperature $100{ }^{\circ} \mathrm{C}$ used as a negative control has a fairly high yield $(26.17 \%)$, as reported in the previous publications. ${ }^{2}$ This can be attributed to the potential contamination of $\mathrm{CaO}$ curing solids in 
the goatskin matrix which is not neutralized and dissolved by washing using running water. Besides, high extraction temperatures, especially at the second and third extractions, each performed at 70 and $100{ }^{\circ} \mathrm{C}$ have increased the potential for contamination of gelatin yield by the crushed skin matrix even after filtration using two layers of fabric.

In general, the neutralization process using a dilute acid solution was required to react with the base curing particles to form a neutral salt which will facilitate the increased solubility of the curing particles in the washing process using running water in the after. Besides, the occurrence of swelling due to acid pretreatment, as reported, has optimized the neutralization of curing particles deposited in the goatskin matrix. ${ }^{9}$ On the other hand, the application of lower extraction temperatures, particularly at the second and third extractions, under $70{ }^{\circ} \mathrm{C}$ is required to optimize the yield without causing damage to the goatskin matrix extracted.

The application of the neutralization process using a dilute acid solution with increasing time (5 to 25 minutes) has an increased yield of $0.78 \%$. Increased neutralization time has provided the optimum contact time for the decomposition of collagen triple helix structure into a smaller double helix, making it easier to extract and then hydrolyzed to gelatin.

Increasing the third extraction temperature from 64 to $68{ }^{\circ} \mathrm{C}$ also showed a similar pattern, where the yield increase was detected from 5.95 to $10.41 \%$ in the application of 25 minutes of neutralization time. This yield was lower than had reported in previous publications, i.e. $26.17 \%$. This condition is related to the maximum contamination caused by curing particle and the matrix of goatskin which is also extracted and counted as yield under extreme extraction conditions. In other words, although the yield is high, the purity of gelatin obtained from this condition is predicted to be not too high.

The results are consistent with those published by previous researchers who reported a decrease in the gelatin yields of whiptail stingray (Dasyatis Brevis) skin along with a more optimal post-curing neutralization process carried out and a decrease in the yields of seabass (Lates calcarifer) skin gelatin at low-temperature extraction. ${ }^{29,30}$ The highest yield $(10.41 \%)$ were obtained from the post-curing neutralization using a dilute acid solution for 25 minute and third extraction temperature of $68{ }^{\circ} \mathrm{C}$.

Table-1: Gelatin Yield From Different Neutralization Times And Temperature of Extraction

\begin{tabular}{c|c|c|c}
\hline $\begin{array}{c}\text { Peutralization Time } \\
\text { (minute) }\end{array}$ & $\begin{array}{c}\text { Extraction } \\
\text { Temperature }\left({ }^{\circ} \mathrm{C}\right)\end{array}$ & Gelatin Code & Yield (\%) \\
\hline 5 & 64 & GSG-1 & $5.17 \%$ \\
\hline 15 & 64 & GSG-2 & $5.49 \%$ \\
\hline 25 & 64 & GSG-3 & $5.95 \%$ \\
\hline 5 & 66 & GSG-4 & $6.91 \%$ \\
\hline 15 & 66 & GSG-5 & $7.58 \%$ \\
\hline 25 & 66 & GSG-6 & $8.32 \%$ \\
\hline 5 & 68 & GSG-7 & $8.95 \%$ \\
\hline 15 & 68 & GSG-8 & $8.40 \%$ \\
\hline 25 & 68 & GSG-9 & $10.41 \%$ \\
\hline
\end{tabular}

\section{Water Content}

Water content is closely related to the shelf life of a product, especially in terms of metabolic activity that takes place. The presence of water in food products becomes one of the factors that influence metabolic activity such as enzymatic and non-enzymatic, microbial and chemical activity, thus potentially causing changes in nutritional value and organoleptic properties. Goatskin gelatin water content under base curing with the varying time of neutralization and extraction temperatures were shown in Table- 2 .

The goatskin gelatin water content produced with different pre-treatment and extraction conditions in this study varied in the range of 3.09-11.60\%. The water content of goatskin gelatin produced with 5 minutes neutralization time and extraction temperature of $68{ }^{\circ} \mathrm{C}$ was not significantly different from the previous study, which was only $5-10 \% .^{2}$

The application of a short neutralization time ( 5 minutes) is predicted to have no major effect on the collagen triple helix structure decomposition. A large number of water molecules trapped in the triple 
helix complex structure produces gelatin with high water content. Increased further neutralization time (15-25 minutes) showed a significant change in gelatin water content. This condition is predicted to be closely related to the decomposition of the triple helix collagen structure which generally becomes a double helix in the base procedure. The simpler molecular structure of collagen has facilitated the evaporation of water molecules, thereby reducing gelatin water content.

Although not significant, an increase in the third extraction temperature of $2{ }^{\circ} \mathrm{C}$ appeared to produce an increase in gelatin water content. This is because the increase in temperature from 64 to $68{ }^{\circ} \mathrm{C}$ only causes degradation of the collagen triple helix structure without causing further decomposition of the goatskin matrix. Furthermore, the extraction temperature applied in this study is predicted to be hot enough to trigger the decomposition of a small amount of collagen triple helix structure into a smaller double helix, but it is cold enough to only trigger a loosening of the connecting bond on a triple helix structure. This condition ultimately makes it easier to enter $\mathrm{H}_{2} \mathrm{O}$ molecules in the structure and then inhibits the optimal drying process. The higher the extraction temperature applied, the higher the molecular quantity of $\mathrm{H}_{2} \mathrm{O}$ that enters and difficult to evaporate at the drying stage, thus triggering an increase in gelatin water content. However, the effect of increasing extraction temperatures at higher levels is being studied.

These results are consistent with previous publications that report an increase in gelatin water content resulting from mild pretreatment, which corresponds to a higher amount of triple-helix structure, and an increase in gelatin water content from shark skin and chicken feet material along with the application of higher extraction temperatures. ${ }^{22,31-33}$ The highest water content of goatskin gelatin $(11.60 \%)$ was obtained from the neutralization process using a dilute acid solution for 5 minutes and a third extraction temperature of $68^{\circ} \mathrm{C}$. However, this water content was still below the water content value required by the Standard National Indonesia (SNI) 06-3735-1995, which amounted to $16 \%$.

Table-2: Gelatin Proximate From Different Neutralization Times and Temperature of Extraction

\begin{tabular}{c|r|c}
\hline \multirow{2}{*}{ Gelatin Code } & \multicolumn{2}{|c}{ Proximate Analysis } \\
\cline { 2 - 3 } & Water Content (\%) & Ash Content (\%) \\
\hline GSG-1 & 10.83 & 2.45 \\
\hline GSG-2 & 5.49 & 2.89 \\
\hline GSG-3 & 3.09 & 3.81 \\
\hline GSG-4 & 11.55 & 2.31 \\
\hline GSG-5 & 9.43 & 2.59 \\
\hline GSG-6 & 5.00 & 3.05 \\
\hline GSG-7 & 11.60 & 2.01 \\
\hline GSG-8 & 9.75 & 2.22 \\
\hline GSG-9 & 7.63 & 2.28 \\
\hline
\end{tabular}

\section{Ash Content}

Determination of ash content is one way to know the level of purity of a material. Ash is an inorganic residue of the combustion of organic matter. The ash content of goatskin gelatin products produced under different pre-treatment and extraction conditions is presented in Table-2. The goatskin gelatin ash content produced by neutralization using a dilute acid solution in this study was entirely below the ash content resulting from previous studies.

In previous publications, reported yields of type B goatskin gelatin with ash levels exceeding the GMIA standard, viz $0.5-2 .^{2}$ This condition is predicted to be closely related to the non-optimum neutralization process carried out by running water in the reduction of base curing particles especially adsorbed and deposited in the goatskin matrix. The conditions were exacerbated by the application of high-temperature $\left(60{ }^{\circ} \mathrm{C}\right.$ at first, $70{ }^{\circ} \mathrm{C}$ at second, $100{ }^{\circ} \mathrm{C}$ in third extraction) and long duration (4-6 hours) extraction processes, which had damaged most of the bonds in the goatskin matrix and facilitates the release of most unneutralized curing particles into the gelatin extract. Under these conditions, the presence of large amounts of curing particles will result in the high ash content of gelatin products. This result is in line with the previous findings that report high ash contents on chicken skin-based gelatin which does not get the post-curing neutralization stage using acid/base. ${ }^{34}$ 
In this study, the implementation of post-curing neutralization with increasing time has increased the gelatin ash content obtained. The results of the analysis showed an increase in ash content $0.74 \%\left(66{ }^{\circ} \mathrm{C}\right)$ at an increase in neutralization time from 5 minutes to 25 minutes. The longer contact time between the skin material and hydrochloride acid, on the one hand, will optimize the neutralization of base curing particles which are deposited on the skin matrix so that it has the potential to reduce the $\mathrm{pH}$, but on the other hand has triggered an increase in ash content induced by an increase in the number of chloride anions which might be extracted. This fact is consistent with previous publication, who reported an increase in gelatin ash content along with an increase in the neutralizing acid concentration, which in this case using $\mathrm{H}_{3} \mathrm{PO}_{4}{ }^{35}$

Slightly different from the neutralization times effect, the increase in third stage extraction from 64 to $68^{\circ} \mathrm{C}$ has reduced the gelatin ash content. This is contrary to that reported by the previous publication, who reported an increase in ash content along with the increase in extraction temperature. ${ }^{36}$ Increasing extraction temperature with a minimum difference $\left(2^{0} \mathrm{C}\right)$ tends to only cause collagen triple helix structure damage without triggering further damage to the goatskin matrix. Degradation limited to the triple helix structure of collagen will only induce curing particle release in this specific location, while damage to the goatskin matrix tends to release most curing particles deposited in it. Although it is predicted that it does not occur significantly, the decomposition of the triple helix structure into a double helix that has a smaller molecular size will increase the potential for the release of curing particles deposited in it. The minimum increase in the extraction temperature applied causes insufficient energy to stretch the bonds to the goatskin matrix and release the particles into the extract. Thus, increasing the extraction temperature, in this case, will facilitate the extraction of collagen protein without increasing in gelatin ash content.

This finding is in line with the previous publication which reported decreased ash content in the fish skin gelatin ash content which produced through the extraction with increasing temperature. ${ }^{37}$ The optimum ash content (meeting the GMIA requirements) resulted from the neutralization time in the range 5-25 minutes with extraction temperatures in the range $64-68^{\circ} \mathrm{C}$.

\section{Gel Strength}

The most important functional property and determinant of the physical quality of gelatin is the gel strength. This parameter is influenced by concentration, intrinsic strength, $\mathrm{pH}$, temperature, and additives in it. The gelatin intrinsic strength is a function of molecular structure and mass. This is in line with the previous statement which states that gel strength is the function of complex interactions that are influenced by the molecular weight distribution, amino acid composition with $\alpha$-chain ratio and $\beta$ component quantity. ${ }^{38-39}$

High gel strength gelatin is generally characterized by the presence of high molecular weight polypeptides because low molecular weight peptides have low potential to effectively form inter-junction zones. ${ }^{9}$ It is also influenced by the content of amino acids (proline and hydroxyproline). ${ }^{40}$ But between the two, hydroxyproline more influences the strength of the gel mainly due to the formation of hydrogen bonds by the -OH functional group. ${ }^{41}$

The first stage in the gelation stage is the formation of locally ordered areas caused by random partial renaturation of gelatin into helices such as collagen. In subsequent stages, there will be a continuous fibrillar three-dimensional network of fringed micelles forms throughout the system caused by the formation of non-specific bonds between more ordered chain segments. Hydrophobic and hydrophilic interactions, as well as hydrogen bonds, may be involved in the formation of crosslinks. The stability of this bond is influenced by heating, thus resulting in the thermo-reversible gel. The formation of a crosslinking is the slowest stage of this process, so under ideal conditions, an increase in gel strength will occur with an increase in the crosslinking time. The total effect that arises is the time-dependent increase in average molecular mass and regularity.

The gel strength of all goatskin gelatins (GSG) resulting from different pre-treatment and extraction conditions in this study has high values (Fig.-1). GSG-1, GSG-2, and GSG-3 show respective gel strength values of $155.25 ; 283.12$; and 218.66 bloom. The analysis showed an increase in gel strength when the neutralization time was increased from 5 minutes to 15 minutes for an extraction temperature of $64{ }^{\circ} \mathrm{C}$. This is caused by more optimal inhibition of the further process of decomposition in the collagen structure 
by the base curing particles deposits remaining in the goatskin matrix. Thus, as a consequence, there will be more crosslinking remaining between more ordered chain segments. The higher molecular weight formed from this condition increases in the gel gelatin product of goatskin gelatin.

Besides, neutralization that is not optimal will cause a high breaking of the bond, especially in structures that bind negatively charged functional groups, as in the reaction shown in Fig.-1.

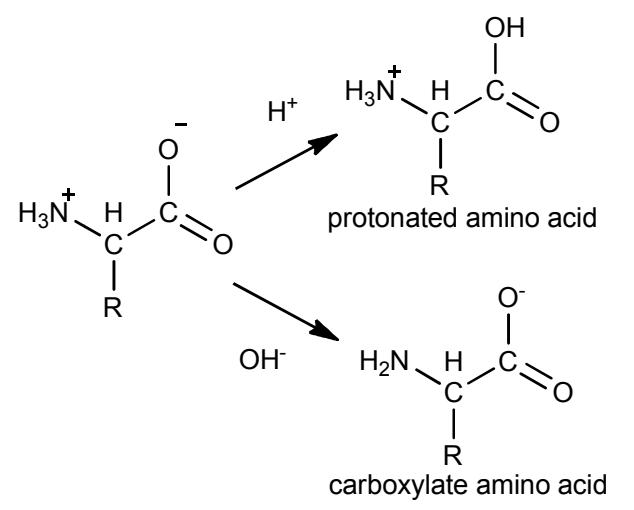

Fig.-1: Amino Acid Reactions in Acidic and Alkaline Environments

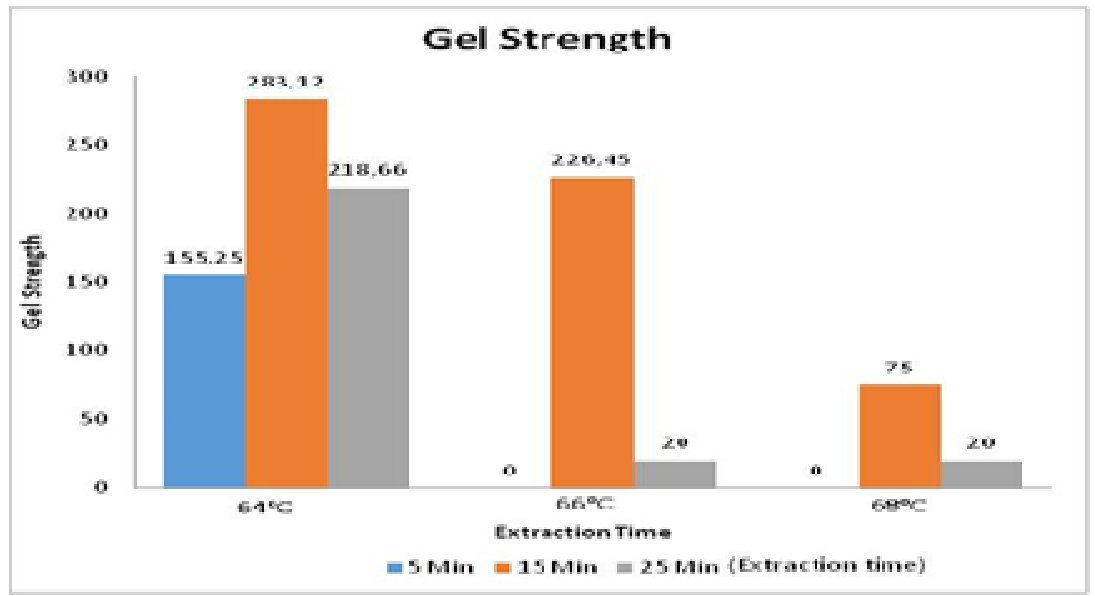

Fig.-2: Gelatin Gel Strength From Different Neutralization Times and Temperature Of Extraction

Specifically, a further increase in neutralization time (15 to 25 minutes) showed the opposite results, which detected a decrease in gel strength of $22.77 \%$. This is predicted to be related to the effect of $\mathrm{HCl}$ which not only neutralizes curing particles but also triggers the termination of many non-specific bonds, especially with positively charged functional groups (See Fig.-1).

The Increasing of the extraction temperature appears to cause a significant reduction in gelatin gel strength. Theoretically, increasing the extraction temperature will cause many bonds and/or interactions in the gelatin structure broken. This condition results in gelatin products with lower molecular weight and gel strength. For example, in Fig. 2 appears that GSG-2; GSG-5; and GSG-8 respectively yield gel strength of $283.12 ; 226.45$; and 75 bloom.

\section{Viscosity}

The second most important physical property of gelatin is viscosity. ${ }^{42}$ The breaking of the hydrogen bonds and the electrostatic interactions present in collagen has caused denaturation. In this condition, there has been degradation of the triple helix structure of collagen protein into a double and single helix which produces high viscosity solution in water. ${ }^{10}$

In this study, it has been obtained viscosities of 26.4; 19.3; and 7.5 mps respectively for GSG-1, GSG-2, and GSG-3 (Fig.-3). Viscosity appears to decrease with increasing time of neutralization being applied. 
The optimal process of neutralizing curing particles in the goatskin matrix as a result of a 30-days curing process has inhibited the further activity of curing particles in breaking down the structure of collagen triple helix and reducing the existence of gelatin molecules with high viscosity in water.

Theoretically, not only the neutralizing time affects the viscosity of gelatin produced, but also the temperature of the extraction. The increase in extraction temperature from 64 to $66{ }^{\circ} \mathrm{C}$ has induced an increase in the gelatin yield in the water medium. The properly increasing in the extraction temperature will induce the collagen triple helix decomposition of the which facilitates the collagen particles to be extracted and then hydrolyzed to gelatin in water. The increase in the presence of gelatin in water has triggered an increase in viscosity at this specific temperature.

However, a further increase in extraction temperature (reaching $68^{\circ} \mathrm{C}$ ) showed the opposite result, where a decrease in viscosity of the gelatin solution was detected, although not as low as the gelatin viscosity obtained in extraction using a temperature of $64{ }^{\circ} \mathrm{C}$. Extraction temperatures that have exceeded the optimum conditions are predicted to cause further damage to the collagen structure that has been extracted and hydrolyzed in water. Low molecular weight gelatin produced from this process causes low viscosity in water. This is evident from the GSG-1 viscosity value (26.4 mps) which increases to $39.4 \mathrm{mps}$ in GSG-4 and then decreases to $35.0 \mathrm{mps}$ in GSG-7. This is in line with the findings in the previous studies. $^{2}$

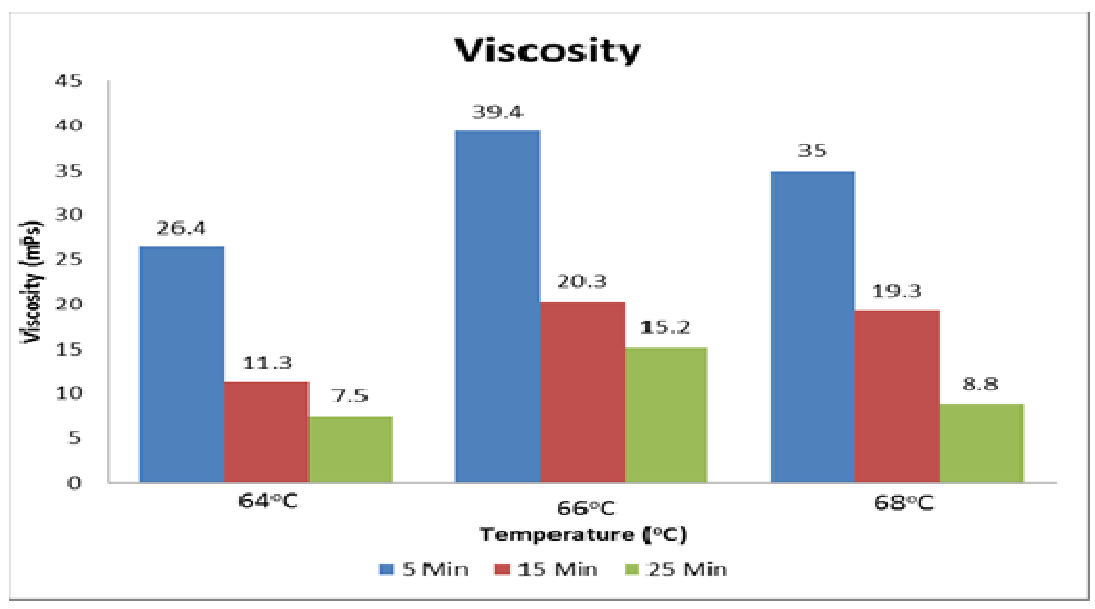

Fig.-3: Gelatin Viscosity from Different Neutralization Times and Temperature of Extraction

Some of the goatskin gelatin products obtained in this study (GG-1, GG-4, GG-7, and GG-8) fulfilled the viscosity required by GMIA, which is $20-75$ mps. Besides, GSG-1 to GSG-9 has a higher viscosity than commercial goat gelatin which is $9.80 \mathrm{cP}^{43}$ In addition to molecular weight, polydispersity triggers this condition, which means polypeptides with high molecular weight produce gelatin with high viscosity. ${ }^{44}$

Gelatin with low viscosity tends to form a gel texture that is short and brittle. While gelatin with high viscosity will be able to form a gel texture that is tough and can be extended. Gelatin like this has a higher commercial value. ${ }^{45}$ The relatively high viscosity obtained in this gelatin may be closely related to the larger particle size and molecular weight of collagen obtained in this study as a result of denaturation engineered by application of specific neutralization time and extraction temperature.

\section{pH}

The $\mathrm{pH}$ of the gelatin solution reflects the chemical treatments used during the extraction. ${ }^{46}$ The observed $\mathrm{pH}$ of gelatin which produced from the application of neutralization time variation showed significantly different results as the higher extraction temperature was applied (Fig.-4).

The highest $\mathrm{pH}$ (7.44) recorded for GSG-7 and lowest for GSG-8 (5.80). The Previous publication had reported that commercial goatskin gelatin $\mathrm{pH}$ was $5.48 .{ }^{43}$ A decrease in $\mathrm{pH}$ value along with an increase in the neutralization time was predicted to be strongly influenced by the residual deposits of base curing particles in the goatskin matrix which was not properly neutralized and washed out in the post-curing 
neutralization stage. This result is reinforced by the fact that the $\mathrm{pH}$ value is lower as the longer neutralization time is applied.

In addition to the time of neutralization, the application of different extraction temperatures also showed significantly different results (Fig.-4). An increase in $\mathrm{pH}$ value, in this case, is predicted to be the result of the decomposition of the collagen triple helix structure has triggered the release of residual deposits of base particles that have not been neutralized properly from this structure.

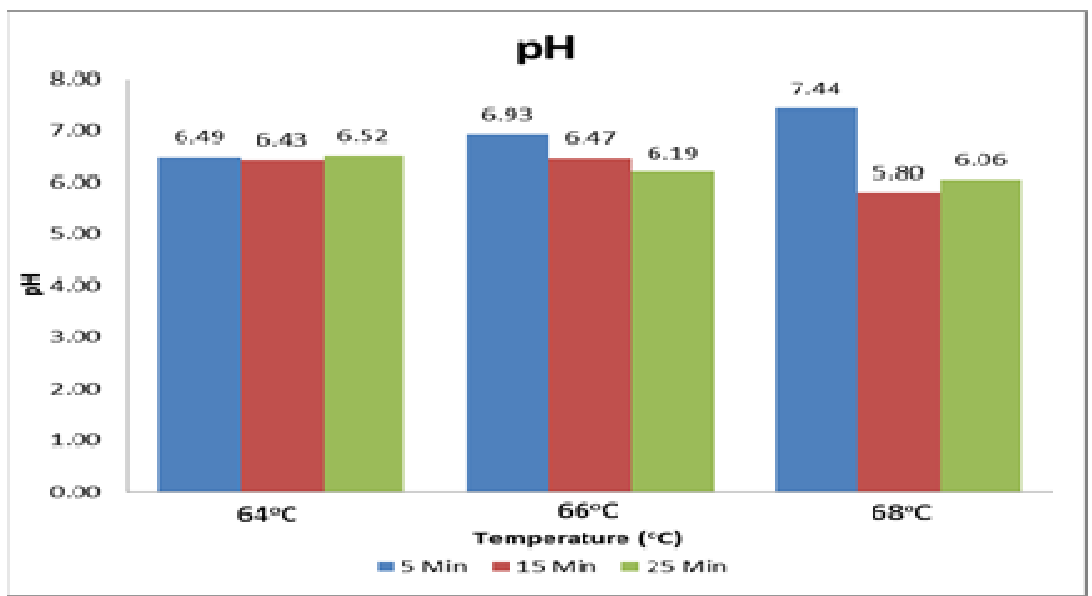

Fig.-4: Gelatin pH from Different Neutralization Times and Temperature of Extraction

Unlike the large calcium $(\mathrm{Ca})$ and chloride $(\mathrm{Cl})$ minerals which tend to be held in the goatskin matrix after the decomposition of triple helix structures, hydrogen $(\mathrm{H})$ and oxygen $(\mathrm{O})$ which are smaller, tend to be extracted together with collagen. This then causes the opposite effect of extraction temperature on ash content and $\mathrm{pH}$.

The obtained $\mathrm{pH}$ of gelatin is an important parameter considering the functional properties of gelatin produced depending on the $\mathrm{pH} .{ }^{16}$ Because of this, the potential utilization of gelatin produced depends on the pre-treatment method used. Overall, the $\mathrm{pH}$ of goatskin gelatin produced in this study has a value of 5.80-7.44 on the base-basis production and this value has met the $\mathrm{pH}$ requirements determined by GMIA, 5.0-7.5. The goat gelatin produced in this study has a lower $\mathrm{pH}$ value than that published in the previous study. ${ }^{2}$

\section{Organoleptic Properties}

GSG-1 showed lower L* values and higher $\mathrm{a}^{*}$ and $\mathrm{b}^{*}$ compared with GSG-2. This shows that GSG-1 has a darker color compared to GSG-2 which is produced with a longer neutralization time. At the same time, GSG-1 also shows a lack of reddish and yellowish color shades (see Table-3). However, the opposite phenomenon in the form of a decrease in the value of $\mathrm{L}^{*}$ as well as an increase in $\mathrm{a}^{*}$ and $\mathrm{b}^{*}$ is detected after a further increase in neutralization time (GSG-3). Dark colors in gelatin are generally caused by inorganic, protein and muco-substance contaminants, introduced or not removed during its manufacture. ${ }^{47}$ The application of a long time acid neutralization in the production of GSG-2 has triggered the activation of a large number of unsaturated bonds (double bonds) through the binding of hydrogen atoms from $\mathrm{HCl}$ compounds. This will reduce the number of specific chromophore and auxochrome (color generator), resulting in the occurrence of hypochromic events. Thus, GSG-2 tends to absorb electromagnetic waves in the ultraviolet (UV) region and produce higher $\mathrm{L}^{*}$ as well as lower $\mathrm{a}^{*}$ and $\mathrm{b}^{*}$ values.

Further increase in neutralization time (25 minutes) in the production of GSG-3, GSG-6, and GSG-9 again showed a decrease in brightness and an increased tendency to form reddish and yellowish colors. This is predicted to be closely related to the interruption of many crosslinking on the structure of collagen compounds that induce the decomposition of the triple helix structure as previously discussed. The decomposition of a large number of crosslinking on the structure of collagen compounds has increased the number of unsaturated bonds (chromophore) which facilitates the absorption of electromagnetic waves in the higher wavelength (bathochromic event), thus triggering darker colors to appear. 
In general, the results of the colorimetric analysis of all samples of goatskin gelatin showed a slightly yellow color, as characterized by the coordinate $b^{*}$ values of each type of gelatin. According to the previous publication, the color of gelatin is influenced by raw materials. ${ }^{48}$ However, although the goatskin gelatin produced in this study was obtained from the same raw material, there was still a change of gelatin color resulting from the variation of neutralization time and extraction temperature. Thus, the color of gelatin is also significantly influenced by the post-curing treatment (neutralization time) and extraction temperature selected.

This fact was further reinforced by the results of gelatin analysis which almost entirely showed the same pattern, namely a decrease in $\mathrm{L}^{*}$ notation along with an increase in extraction temperature, but with a change in $\mathrm{a}^{*}$ and $\mathrm{b}^{*}$ notations which varied slightly. The decrease in brightness, in this case, is closely related to the more optimal decomposition of collagen triple helix structure which induces the formation of double bonds as a result of the decomposition of a large number of crosslinking in the structure. This condition will enrich the type and quantity of chromophore which is responsible for color absorption. Associated with the existence of the neutralizing time and the extraction temperature as the two factors of the bathochromic trigger or the shift of light adsorption to a higher wavelength, the extraction temperature has resulted in a darker goatskin gelatin product.

For the record, all the goatskin gelatin produced in this study has $\mathrm{L}^{*}$ notation that exceeds $100 \%$. This value is produced as a result of measuring the brightness level of gelatin using a standard which tends to be darker in color. This is in line with the one previous publication which reports that $\mathrm{L}^{*}$ notation can be slightly higher than $100 \%$ in some cases with samples that are brighter than standard/reference at standard wavelengths. ${ }^{49}$ In this regard, commercially available gelatin with the specifications described in the method section is used as a standard.

Table-3: Gelatin Organoleptic Properties from Different Neutralization Times and Temperature of Extraction

\begin{tabular}{c|c|c|c}
\hline \multirow{2}{*}{ Gelatin Code } & \multicolumn{2}{|c}{ Colour Parameters } \\
\cline { 2 - 4 } & $\mathrm{L}^{*}$ & $\mathrm{a}^{*}$ & $\mathrm{~b}^{*}$ \\
\hline GSG-1 & 120.07 & 2.38 & -29.88 \\
\hline GSG-2 & 135.05 & 1.39 & -44.24 \\
\hline GSG-3 & 129.50 & 2.62 & -37.61 \\
\hline GSG-4 & 118.03 & 1.99 & -30.20 \\
\hline GSG-5 & 123.07 & -0.12 & -28.37 \\
\hline GSG-6 & 115.30 & -0.60 & -20.79 \\
\hline GSG-7 & 125,72 & 1,37 & $-35,70$ \\
\hline GSG-8 & 122.44 & 1.32 & -31.54 \\
\hline
\end{tabular}

\section{Fourier Transform Infra-Red Spectra}

FTIR spectroscopy is commonly applicated to analyze functional groups and secondary structures of gelatin. The amide-I band is the main secondary protein structure to be observed using infrared spectroscopy. ${ }^{27,50}$ The Amide-I peaks are formed by a combination of $\mathrm{C}=\mathrm{O}$ stretching vibrations, hydrogen bonds coupled with contributions from $\mathrm{CN}$ stretching, $\mathrm{CCN}$ deformations, and in-plane $\mathrm{NH}$ bending. ${ }^{51}$ The exact location of the Amida-I peak is determined by hydrogen bonds and protein structure conformation. ${ }^{52}$ The Amide-I peak was found in the wavenumber range of $1,600-1,700 \mathrm{~cm}^{-1} .^{53}$ The observed absorption peak at the wavenumber $1,633 \mathrm{~cm}^{-1}$ is a characteristic coiled gelatin structure and this corresponds to the observed results of the amide-I peak obtained in the range $1,631-1,635 \mathrm{~cm}^{-1} .54$

The FTIR spectrum shows that the major peaks of GSG-1, GSG-2, GSG-3, and GSG-4 were detected at the amide region and the different peak positions of the band as well as its intensity are presented in Fig.5 (a) and (b). ${ }^{53}$

In this analysis, FTIR commercial gelatin spectra (CGG) were used as a comparison. The Amide-I peaks for GSG-1, GSG-2, GSG-3, GSG-4 and CGG were detected at 1,628.73; 1,627.73; 1,627.77; 1,628.65; and $1,628.62 \mathrm{~cm}^{-1}$. The shift of amide-I absorption peak (GSG-1 $\rightarrow$ GSG-3) to lower wavenumbers is predicted to be closely related to molecular structure deformation due to the release of intermolecular crosslinking energy in the collagen triple helix structure which in the next stage will form a double bond. 
This fact shows the influence of post-curing neutralization time which is increasing towards the infrared absorption shift triggered by the decomposition of the triple helix structure of collagen.

Furthermore, the shift of the Amide-I peak in the GSG-1 and GSG-4 infrared spectra showed the same pattern. Increasing the extraction temperature from $64{ }^{\circ} \mathrm{C}$ on GSG- 1 to $66{ }^{\circ} \mathrm{C}$ on GSG- 4 has triggered the decomposition of the collagen triple helix structure, and as a consequence, a double bond is formed which results in a shift of infrared absorption peak to a lower wavenumber. The lower wavenumbers are indicated by the amide-I peak of CGG compared to the gelatin samples, a greater triple helix decomposition in CGG.

Amide-II absorption peaks of GSG-1, GSG-2, GSG-3, and CGG were observed in 1,527.71; 1,520.09; 1,531.26; and 1,522.72 $\mathrm{cm}^{-1}$, respectively. Amide-II peak is a combination of phase-out CN strain and inplane NH deformation of peptide groups. ${ }^{55,56}$ The IR spectrum of dry collagen has an amide-II absorption peak in the range of $1,530 \mathrm{~cm}^{-1}-1,540 \mathrm{~cm}^{-1}$. This peak appearance is generally accompanied by the appearance of small peaks at low frequencies. ${ }^{56}$ Lower wavenumbers, in this case, indicate higher involvement of $\mathrm{NH}$ functional groups in the formation of hydrogen bonds with neighboring molecules. ${ }^{56}$ Compared with CGG, only GSG-2 shows a wavenumber lower than CGG. This shows the greater role of the $\mathrm{NH}$ group in the H-bond.

Furthermore, the Amide-III peak which presents the C-N stretching and $\mathrm{N}-\mathrm{H}$ deformation in the plane bending induced by the amide linkages and absorption triggered by the wagging vibrations of the $\mathrm{CH}_{2}$ group from the backbone of glycine and the proline side chain is generally detected in the wavenumber $1,200-1,400 \mathrm{~cm}^{-1}$. ${ }^{56}$ The Amide-III peaks on GSG-1; GSG-2; GSG-3; GSG-4, and CGG each appear at wavenumber $1,235.26 ; 1,237.24 ; 1,238.18 ; 1,238.44$; and $1,235.65 \mathrm{~cm}^{-1}$.

The appearance of the Amide-III peak in the wavenumber $1,233 \mathrm{~cm}^{-1}-1,234 \mathrm{~cm}^{-1}$ indicates the loss of the collagen triple helix structure. This condition is predicted to be related to the interference in the molecular structure of gelatin, which in this study was induced by neutralization and extraction conditions. Lower wavenumbers from the Amide-III peak indicate changes in the $\alpha$-helix to randomly coiled structure triggered by the loss of triple helix structure due to denaturation of collagen proteins which subsequently forms gelatin. ${ }^{30,53}$

The low wavenumber of GSG-2, which is slightly above $1,234 \mathrm{~cm}^{-1}$, shows changes in the $\alpha$-helical structure of GSG-2 into a randomly coiled structure that can occur due to the termination of many nonspecific bonds by neutralizing compounds ( $\mathrm{HCl}$ ). Amide-III peaks from GSG-4 are detected at the highest wavenumbers, indicating loss of triple helix configuration as a result of the application of higher extraction temperatures. Meanwhile, the Amide-III peak from GSG-1 at the lowest wavenumber, which is closest to $1,234 \mathrm{~cm}^{-1}$, shows the minimum changes that occur in the triple helix structure of collagen protein due to the application of the mildest neutralization and extraction conditions. The same wavenumber is also indicated by the CGG Amide-III peak. many additional peaks detected in the infrared spectra of all gelatin samples with wavenumbers below $1,233 \mathrm{~cm}^{-1}$ showed C-O stretching vibrations of short peptide chains. ${ }^{56}$

In addition to the peak of Amide-I, -II, and -III, the presence of Amide-A peaks can also be used to evaluate further levels of denaturation in the triple helix structure of collagen proteins. The Amide A peaks are produced from $\mathrm{NH}$ stretching which coupled with hydrogen bonding, which is generally observed in the range of wavenumbers $3,400-3,440 \mathrm{~cm}^{-1} .{ }^{52}$ When $\mathrm{NH}$ in the peptide is involved with hydrogen bonding, Amide-A peak will shift to lower wavenumbers (generally close to $3,300 \mathrm{~cm}^{-1} .^{57-59}$

In GSG-1, GSG -2, GSG-3, GSG-4, and CGG no infrared spectra peak was observed at Amide-A specific wavenumber. However, peak occurrence was detected in all four gelatin samples and CGG in wavenumber of $3,260-3.276 \mathrm{~cm}^{-1}$. This is predicted to be closely related to the shift in Amide-A absorption peak at lower wavenumbers along with the high involvement of $\mathrm{NH}$ groups in peptides with hydrogen bonding. More specifically, Amide-A peak was detected at $3,274.35 \mathrm{~cm}^{-1}$ on GSG-1; 3,275.44 $\mathrm{cm}^{-1}$ on GSG-2; $3,265.52 \mathrm{~cm}^{-1}$ on GSG-3; $3,274.85 \mathrm{~cm}^{-1}$ on GSG-4; $3,271.33 \mathrm{~cm}^{-1}$ on CGG.

Lower wavenumbers with high amplitude at the Amide-A peak indicate degradation of gelatin. ${ }^{60}$ The Amide-A peaks with low wavenumbers which produced from goatskin samples treated with fairly long neutralization times and quite high extraction temperatures may be related to the high involvement of hydrogen bonds with $\mathrm{NH}$ groups in the $\alpha$-chain. In this regard, GSG-3 shows the appearance of Amide-A 
peak with the lowest wavenumber which shows the highest degradation rate of gelatin in all four samples. Compared to GSG-3, CGG occupies the second-lowest position thereafter. While for GSG-1, GSG-2, and GSG-4, each shows the appearance of Amide-A peak at relatively close wavenumbers. Thus, it is concluded that the secondary structure and functional groups are affected by the neutralization time and the temperature of the extractions.
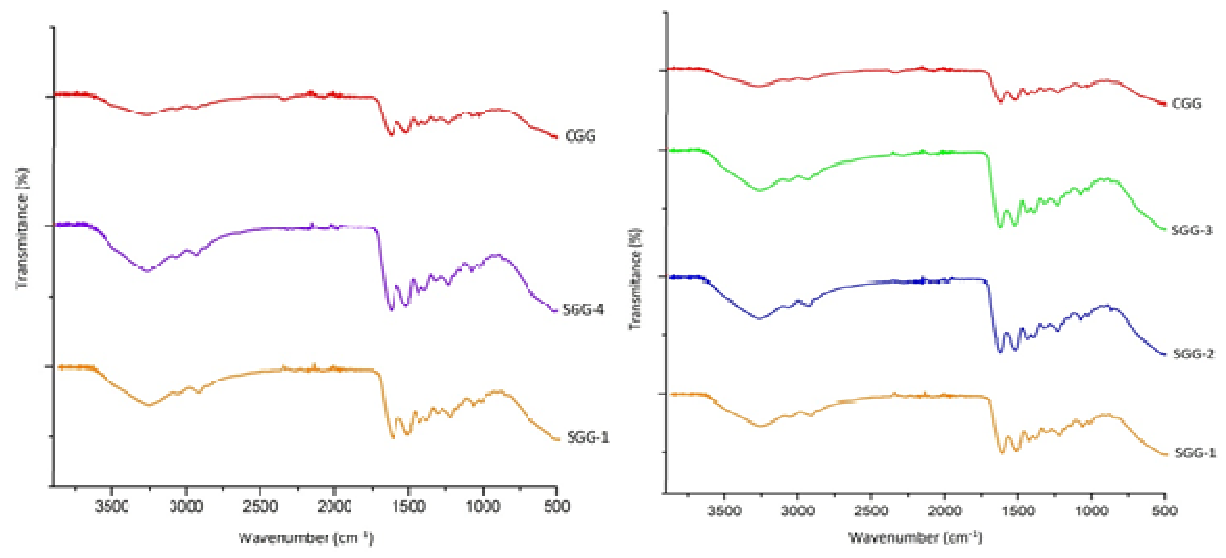

Fig.-5: FTIR Spectra of Goatskin Gelatin with (A) Different Neutralization Time and (B) Extraction Temperature

\section{CONCLUSION}

Pre-treatment of goatskin gelatin by neutralization using $\mathrm{HCl}$ for 5-25 minutes followed by water solvent extraction at $64-68{ }^{\circ} \mathrm{C}$ for 4 hours resulted in gelatin yield significantly different from the previous publication. An increase in the post-curing neutralization for 5 minutes-25 minutes and the extraction temperature for $66^{\circ} \mathrm{C}-68{ }^{\circ} \mathrm{C}$ has resulted in the gelatin yield with the most qualified qualifications set by GMIA. In this condition, gelatin is obtained with the yield percentage of $5.17 \%-10.41 \%$, water and ash content of each $3.09 \%-11.60 \%$ and $2.01 \%-3.81 \%$, gel strength of 20.00 bloom-283.12 bloom, viscosity of 7.5 mps-39.4 mps, pH 5.80-7.44, lightness ( $\left.\mathrm{L}^{*}\right)$ 112.06-135.05, redness ( $\left.\mathrm{a}^{*}\right)-0.60-2.62$, yellowness (b*) -44.24-(-18.24). Most of the goatskin gelatin qualifications produced in this study have met the requirements set by GMIA. The results of FTIR analysis showed the presence of Amide-I, Amide-II, Amide-III, and Amide-A which were not significantly different from commercial gelatin.

\section{REFERENCES}

1. P. Kaewruang, S. Benjakul, T. Prodpran, A.B. Encarnacion, S. Nalinanon, LWT-Food Science and Technology, 59, 482 (2014), DOI:10.1016/j.lwt.2014.07.021

2. A. Bahar, M.A. Anggarani, N. Kusumawati, S. Muslim, Advanced in Social Science, Education and Humanities Research, 171, 62 (2018), DOI:10.2991/snk-18.2018.10

3. Jelita, B. Wirjosentono, Tamrin, L. Marpaung, Rasayan J. Chem., 12(3), 1157 (2019), DOI: 10.31788/RJC.2019.1235378

4. F.W. Artanti, W. Trisunaryanti, M. Pongsendana, Triyono, I.I. Falah, M.F. Marzuki, Rasayan J. Chem., 11(4), 1433 (2018), DOI: 10.31788/RJC.2018.1143073

5. G. Boran, J.M. Regenstein, Advanced in Food and Nutrition Research, 60, 143 (2010), DOI:10.1016/S1043-4526(10)60005-8

6. A. Gennadios, M.A. Hanna, L.B. Kurt, LWT-Food Science and Technology, 17, 350 (1997), DOI:10.1006/fstl.1996.0202

7. K. Ishida, R. Kuroda, M. Miwa, Y. Tabata, A. Hokugo, T. Kawamoto, K. Sasaki, M. Doita, M. Kurosaka, Tissue Engineering, 37, 1112 (2007), DOI:10.1089/ten.2006.0193

8. I. Yakimets, N. Wellner, A.C. Smith, R.H. Wilson, I. Farhat, J. Mitchell, Polymer, 55, 12585 (2005), DOI:10.1016/j.polymer.2005.10.090 
RASĀYAN J. Chem.

Vol. 13 | No. 1 |85 - 98| January - March | 2020

9. A.M.M. Ali, H. Kishimura and S. Benjakul, Food Hydrocolloids, 37, 172 (2018), DOI:10.1016/j.foodhyd.2018.03.052

10. F. Badii and N.K. Howell, Food Hydrocolloids, 20, 640 (2006), DOI:10.1016/j.foodhyd.2005.06.006

11. D. Saha and S. Bhattacharya, Journal of Food Science and Technology, 47, 597 (2010), DOI: $10.1007 / \mathrm{s} 13197-010-0162-6$

12. S. Mad-Ali, S. Benjakul, T. Prodpran, and S. Maqsood, Journal of the Science of Food and Agriculture, 96, 2203 (2016), DOI:10.1002/jsfa.7336

13. T. Joanna, M. Malgorzata, K. Piotr, M. Zajac, Food Hydrocolloids, 81, 179 (2018), DOI: 0.1016/j.foodhyd.2018.02.048

14. S. Benjakul, Y. Thiansilakul, W. Visessanguan, S. Roytrakul, H. Kishimura, T. Prodpran, J. Meesane, Journal of the Science of Food and Agriculture, 90, 138 (2010), DOI:10.1002/jsfa.3795

15. H.I.A. Amqizal, H.A. Al-Kahtani, E.A. Ismail, K. Hayat, and I. Jaswir, Food Control, 78, 303 (2017), DOI:10.1016/j.foodcont.2017.02.024

16. A. A. Karim and R. Bhat, Food Hydrocolloids, 23, 576 (2009), DOI:10.1016/j.foodhyd.2008.07.002

17. B.G. Warmington and A.H. Kirton, Small Ruminant Research, 7, 165 (1990), DOI:10.1016/09214488(90)90089-O

18. M. C. Gómez-Guillén, J. Turnay, M. D. Fernández-Diaz, N. Ulmo, M.A. Lizarbe, P. Mon-tero, Food Hydrocolloids, 16, 34 (2002), DOI:10.1016/S0268-005X(01)00035-2Z

19. Z. Khiari, D. Rico, A.B. Martin-Diana, and C. Barry-Ryan, Journal of Material Cycles and Waste Management, 180, 191 (2017), DOI:10.1007/S10163-015-0399-2

20. I. Lassoued, M. Jridi, R. Nasri, A. Dammak, M. Hajji, M. Nasri, A. Barkia, Food Hydrocolloids, 9, 318 (2014), DOI:10.1016/j.foodhyd.2014.04.029

21. P. Kaewruang, S. Benjakul, and T. Prodpran, Food Chemistry, 11, 1437(2013), DOI:10.1016/j.foodchem.2012.09.114

22. P. Diaz-Calderon, E. Flores, A. Gonzalez-Munoz, M. Pepczynska, J. Quero, J. Enrione, Food Hydrocolloids, 5, 128 (2017), DOI:10.1021/acssuschemeng.7b00719

23. M. I. Said, S. Triatmojo, Y. Erwanto, and A. Fudholi, Agritech, 14, 200(2011), DOI: 10.22146/agritech.9744

24. N. N. Nazmi, M. I. N. Isa and N. M. Sarbon, Food Bioscience, 19, 155(2017), DOI:10.1016/j.fbio.2017.07.002

25. H .Yang, Y. Wang, P. Zhou, and J. M. Regenstein, Food Hydrocolloids, 22, 1550(2008), DOI:10.1016/j.foodhyd.2007.10.007

26. P. Zhou and J. Regenstein, Journal of Food Science, 70, 396(2005), DOI:10.1111/j.13652621.2005.tb11435.x

27. P. Kittiphattanabawon, S. Benjakul, W.Visessanguan, and F. Shahidi, Food Hydrocolloids, 14, 171 (2010), DOI:10.1016/j.foodchem.2009.09.037

28. A. G. Gornall, C.J. Bardawill, M.M. David, Journal of Biological Chemistry, 35, 766(1949), DOI:10.1016/j.foodhyd.2013.08.022

29. M.A. Sa'ntiz-Go'mez, M.A. Mazorra-Manzano, H.E. Ramı'rez-Guerra, S.M. Scheuren-Acevedo, Navarro-Garcı, G. Pacheco-Aguilar, J.C. R. Ramı'rez-Sua'rez, Food Sci Biotechnol., 27, 517 (2018), DOI:10.1016/S0268-005X(01)00023-6

30. S. Sinthusamran, S. Benjakul, and H. Kishimura, Food Chemistry, 276, 284(2014), DOI:10.1016/j.foodchem.2013.11.109

31. H. Yasin, A.S. Babji and A.S. Norrakiah, LWT-Food Science and Technology, 72, 79(2017), DOI:10.1016/j.lwt.2016.11.045

32. Soeparno. 2009, Ilmu dan teknologi daging, $5^{\text {th }}$ edition, Gadjah Mada University Press, Yogyakarta.

33. M. Astawan, P. Hariyad and A.Mulyani, Jurnal Teknologi dan Industri Pangan, 15, 46 (2002), DOI:10.1016/S0268-005X(01)00023-6

34. D. Prihatiningsih, N.M. Puspawati and J. Sibarani, Indonesian E-Journal of Applied Chemistry, 3, 46 (2014)

35. H. Yuniarifin, V.P. Bintoro, and A. Suwarastuti, J. Indonesian Trop. Anim. Agric. 16, 61(2006), DOI:10.1016/S0268-005X(01)00034-0 
RASĀYAN J. Chem.

Vol. 13 | No. 1 |85 - 98| January - March | 2020

36. A. Poedjiadi and F. M. T. Supriyanti, 2006, Dasar-dasar Biokimia, UI Press, Jakarta

37. A. D. Islami, Junianto, and Rostika, Journal of Fisheries and Marine Affairs, 4, 40 (2018),

38. Hydrocolloids, 16, 34 (2002), DOI:10.1016/S0268-005X(01)00035-2

39. R. Balti, M. Jridi, A. Sila, N. Souissi, N. Nedjar-Arroume, D. Guillochon,. Food Hydrocolloids, 9, 50 (2011), DOI:10.1016\%2Fj.foodhyd.2010.09.005

40. A. Jongjareonrak, S. Benjakul, W. Visessanguan, M. Tanaka, Food Hydrocolloids, 16, 1222 (2006), DOI: 10.1016/j.foodhyd.2005.04.007

41. P. Montero, M.D. Fernández-Díaz, and M.C. Gómez-Guillén, Food Hydrocolloids, 97, 205 (2002), DOI: $10.1016 / \mathrm{S} 0268-005 \mathrm{X}(01) 00035-2$

42. A. G. Ward, and A. Courts, The Science and Technology of Gelatin, Academic Press, London, p. 48, 85 (1977)

43. N. F. Mohtar, C. Perera, and S.-Y. Quek, Food Chemistry, 37, 313(2010), DOI:10.1016/j.foodchem.2010.02.027

44. M., Gudmundsson, and H. Hafsteinsson, Journal of Food Science, 7, 47(1997), DOI:10.1111/j.13652621.1997.tb04363.x

45. P. Zhou, S.J. Mulvaney and J.M.Regenstein, Journal of Food Science, 13, 321(2006), DOI:10.1111/j.1750-3841.2006.00065.X

46. A. Da Trindade Alfaro, E. Balbinot, C. I. Weber, I. B. Tonial, and A. Machado-Lunkes, Food Engineering Reviews, 23, 44 (2015), DOI:10.1007/s12393-014-9096-5

47. R. Avena-Bustillos, C. Olsen, D. Olson, B.-s.Chiou, E. Yee, P. Bechtel, and T. McHugh, Journal of Food Science, 52, 2174 (2006), DOI:10.1111/j.1750-3841.2006.00016.x

48. G. Ninan, J. Jose, and Z. Abubacker, Journal of Food Processing and Preservation, 35, 162 (2011), DOI: $10.1111 / \mathrm{j} .1745-4549.2009 .00467 . \mathrm{x}$

49. Ocean Optics, The CIELAB color measurement done in SpectraSuite is done as indicated in CIE 15.3 pages $17-18$ (2004)

50. W. Trisunaryanti, I.I. Falah, D.R. Prihandini, M.F. Marsuki, Rasayan J. Chem., 12(3), 1526 (2019), DOI: $10.31788 /$ RJC.2019.1235297

51. J. Bandekar, Biochimica et Biophysica Acta (BBA) - Protein Structure and Molecular Enzymology, 3, 143 (1992), DOI:10.1016/0167-4838(92)90261-B

52. M. H. Uriarte-Montoya, H. Santacruz-Ortega, F. J. Cinco-Moroyoqui, O. Rouzaud-Sández, M. Food Research International, 27, 3249 (2011), DOI:10.1016/j.foodres.2011.08.018

53. H. Muyonga, C. G. B. Cole and K. G. Duodu. Food Hydrocolloids, 35, 332 (2004b)

54. I. Yakimets, N. Wellner, A. C. Smith, R. H. Wilson , Farhat I, Mitchell. J. Polymer, 17, 12585 (2005), DOI:10.1016/j.polymer.2005.10.090

55. F. Lavialle, R. G. Adams, and I. W. Levin, Biochemistry, 52, 2312(1982), DOI: $10.1021 / \mathrm{bi00539a006}$

56. Z. C. Tu, T. Huang, H. Wang, X. M. Sha, Y. Shi, X. Q. Huang, Z. Z. Man, and D. J. Li, Journal of Food Science and Technology, 54, 1256 (2017), DOI:10.1007/s13197-013-1239-9

57. M. Ahmad and S. Benjakul, Food Hydrocolloids, 25, 388(2011), DOI:10.1016/j.foodhyd.2010.07.004

58. B. Doyle, E. Bendit, and E. R. Blout, Biopolymers, 27, 957(1975), DOI:10.1002/bip.1975.360140505

59. M. Nagarajan, S. Benjakul, T. Prodpran, P. Songtipya, and H. Kishimura, Food Hydrocolloids, 29, 397 (2012), DOI:10.1016/j.foodhyd.2012.04.00

60. M. Jackson. L. Choo, P. H. Watson, W. C. Halliday, and H. H. Mantsch, Biochimica et Biophysica Acta (BBA) -Molecular Basis of Disease, 1, 6 (1995), DOI:10.1016/09254439(94)00056-V

[RJC-5409/2019] 